\title{
Ovesco system for treatment of postpolypectomy bleeding after failure of conventional treatment
}

\author{
Noelia Alcaide, Irene Peñas-Herrero, Lorena Sancho-del-Val, Rafael Ruiz-Zorrilla, Jesús Barrio \\ and Manuel Pérez-Miranda
}

Department of Gastroenterology. Hospital Universitario "Río Hortega". Valladolid, Spain

\begin{abstract}
The clip Ovesco (Ovesco, Tübingen, Germany) is a novel endoscopic method for mechanical compression of tissue in the gastrointestinal tract. The indications for treatment are closure of perforations and fistulas and control of bleeding in which the conventional endoscopic treatment has failed. We report two cases about the use of an Ovesco (over-the-scope clip, OTSC) system to control persistent bleeding postpolypectomy after failure of usual treatment.
\end{abstract}

Key words: Ovesco. Nitinol clip. Hemostasis. Gastrointestinal bleeding.

\section{CASE REPORTS}

\section{Case report 1}

A 65-year-old woman with no medical history of interest underwent gastroscopy due to iron-deficiency anemia. A 4-cm pedunculated polyp with wide stalk in the antrum was noted. Polypectomy was performed with a snare after injection with epinephrine. Immediately, it showed arterial bleeding that was treated unsuccessfully with sclerotherapy with epinephrine and etoxiesclerol and application of endoclips (Olympus, Hamburg, Germany) (Fig. 1 A-C). Therefore, placement of an Ovesco with rounded edges by

Alcaide N, Peñas-Herrero I, Sancho-del-Val L, Ruiz-Zorrilla R, Barrio J, Pérez-Miranda M. Ovesco system for treatment of postpolypectomy bleeding after failure of conventional treatment. Rev Esp Enferm Dig 2014;106:55-58.

Received: 10-06-2013

Accepted: 24-07-2013

Correspondence: Noelia Alcaide. Department of Gastroenterology. Hospital Universitario Río Hortega. c/ Dulzaina, 2. 47012 Valladolid, Spain e-mail: noelialcaide@hotmail.com its insertion in the distal end of a therapeutic gastroscope (Olympus GIF 1TQ160) was decided. Bleeding was very profuse and prevented from locating the bleeding vessel. The anchor was used to bind tissue margins and to pull them into the cap before clip release. Hemostasis was achieved promptly (Fig. 2).

\section{Case report 2}

An ambulatory colonoscopy was performed on a 71-yearold woman for colorectal cancer screening. The patient was carrier of a prosthetic metal heart valve in mitral position. Prior to colonoscopy, oral anticoagulant was retired according to hospital protocol. Two sessile polyps of $15-\mathrm{mm}$ and 20-mm were removed in sigma by a snare polypectomy and previous submucosa injection of epinephrine. Three days after, the patient was admitted into hospital with rectal bleeding. Laboratory test revealed hemoglobin of $9.7 \mathrm{~g} / \mathrm{dL}$. A new colonoscopy was performed, an adherent clot in the proximal polypectomy was observed (Fig. 3). It was removed and two hemoclips were placed. Base of resection from the distal polypectomy was covered with fibrin without bleeding. However, three days later, the patient began with new episode of rectal bleeding. It was noted a clot in the base of resection from the proximal polypectomy and hemoclips were gone. It was placed endoclips and endoloop closure technique (Fig. 4). A clip was applied in the distal polypectomy for added security although it did not show any signs of bleeding. Sodium heparin intravenous infusion was started since it was not possible to reintroduce anticoagulant oral and the risk of recurrent rectal bleeding. The patient was attended again, 48 hours later, because of another episode of rectal bleeding from ulcer caused by clips of the base of resection from proximal polypectomy (Fig. 5A). An OTSC was used at that time because of the failure to control bleeding using conventional endoscopic treatments. Same endoscope and kind of OTSC as in previ- 


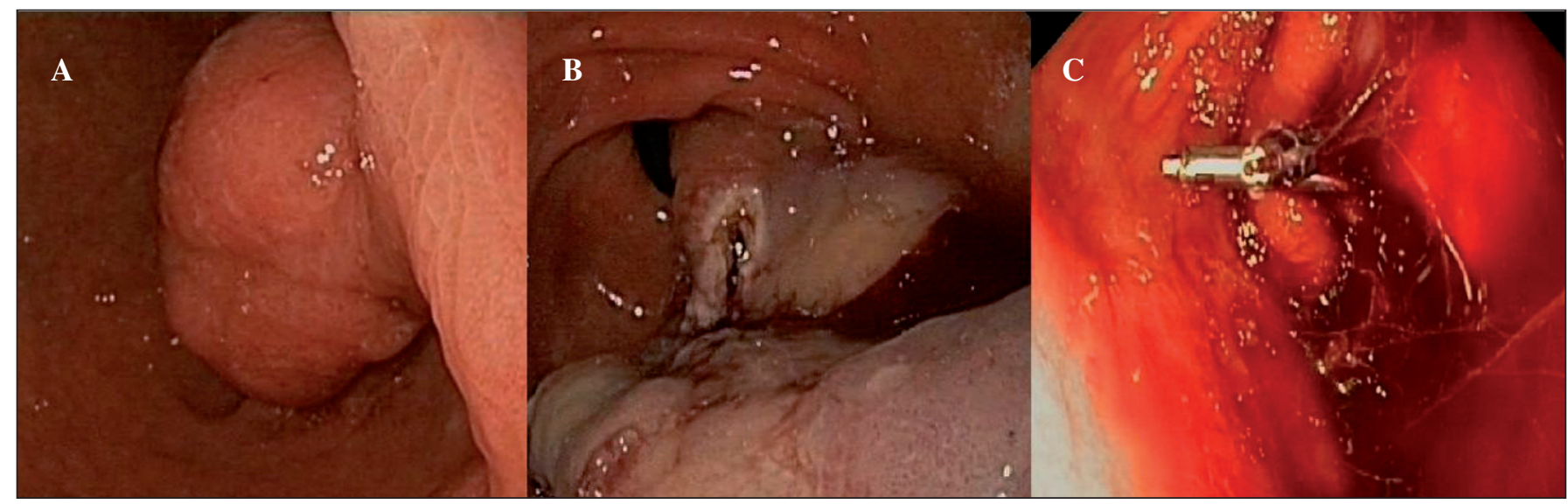

Fig. 1. A. Gastroscopy shows a pedunculated polyp in the antrum. B. Polypectomy was performed with a snare. C. Polypectomy showing evidence of arterial bleeding after epinephrine injection and placement of standard clips.

ous case was used in this patient. An OTSC was positioned in the center of the lesion. The tissue was suctioned into the applicator cap, without application aids like a grasper. The OTSC was released and immediate hemostasis was achieved. There were no complications related to the procedure (Fig. 5 B and C). There were no new episodes of bleeding after reintroducing oral coagulation.

\section{DISCUSSION}

Gastrointestinal bleeding is frequent in clinical practice, and it is an everyday indication for endoscopy pro-

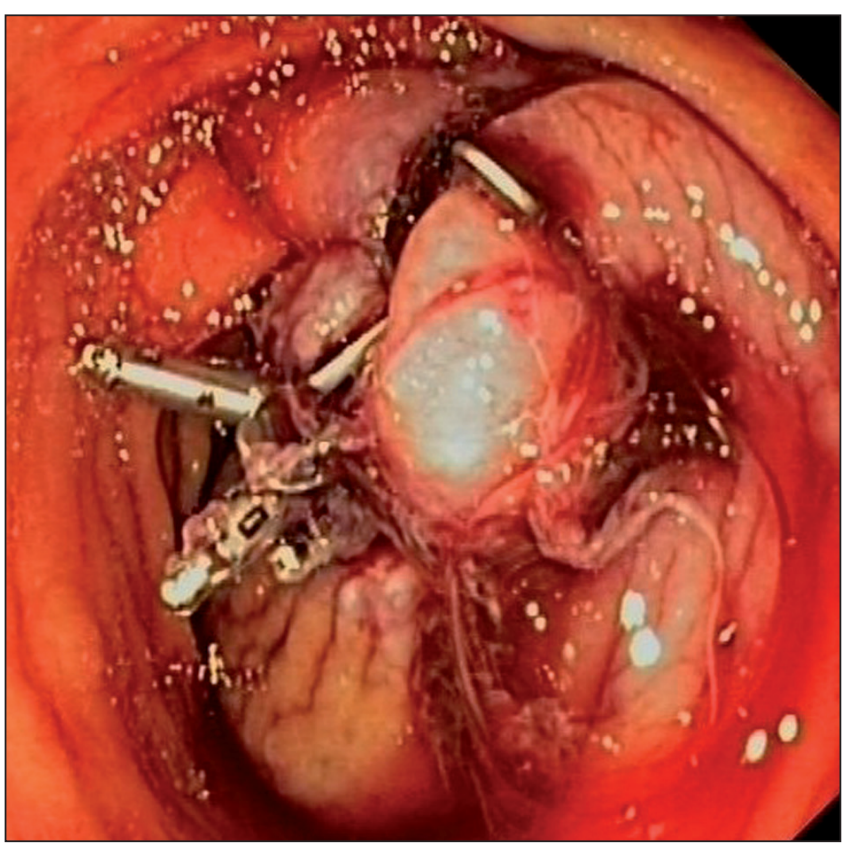

Fig. 2. Treatment of postpolypectomy bleeding after failure of conventional endoscopic therapy by releasing an OTSC. cedures. Conventional endoscopic treatment includes injection, thermal application and through-the-scope clips (TTSCs), they are the gold standard for gastrointestinal bleeding. These techniques have demonstrated their efficacy for bleeding control, and decreased needs of surgery and blood transfusions. However, traditional endoscopic hemostatic methods have limitations and they can fail in a severe bleeding.

TTSCs have some limitations in their use: They are smalls, they just allow the compression of small surface of tissue, and it is quite frequent to use more than one to achieve complete hemostasis. Moreover, sometimes bleeding may get worse after vessel's laceration by TTSCs $(1,2)$.

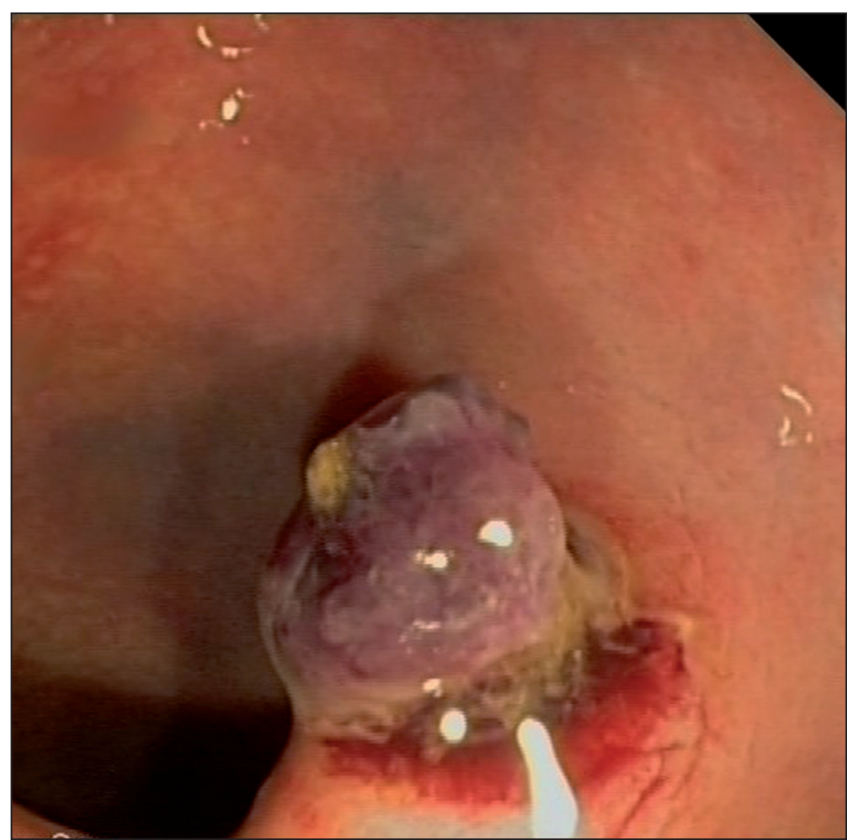

Fig. 3. Bleeding after polypectomy of two sessile polyps in sigma. First bleeding. Adherent clot in the proximal polypectomy. 


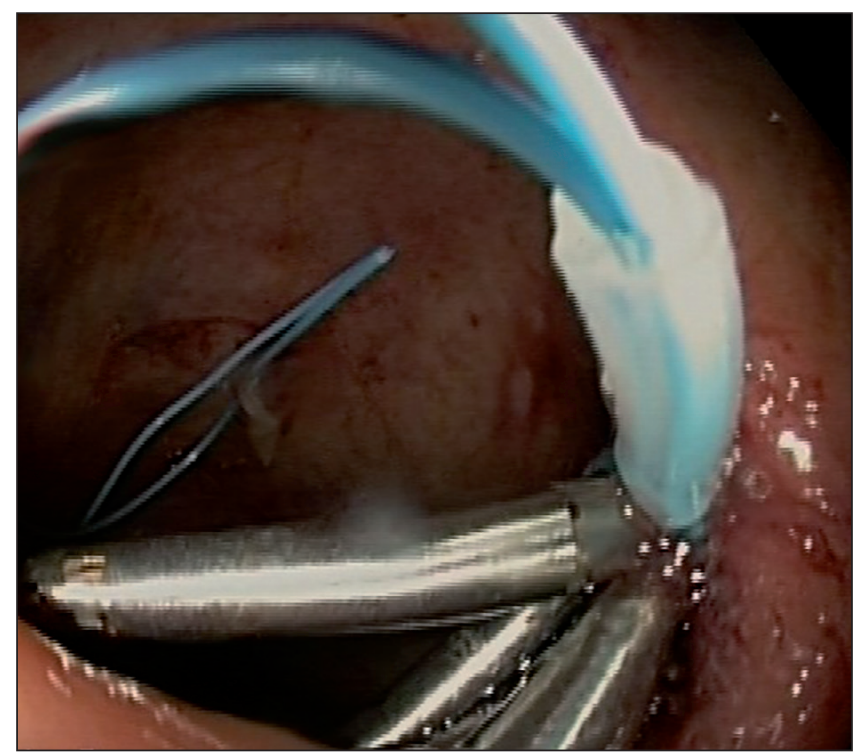

Fig. 4. Second bleeding. Application of endoclips and an endoloop closure technique to achieve hemostasis.

The OTSC is an innovative clipping device made of a nitinol alloy with "shape memory" effect (3). It must be fitted onto the tip of the endoscope by means of a system similar to that used in endoscopic band ligation for esophageal varices. When it is released, it closes and can trap the entire thickness of the bowel wall (4). It is used as a method for mechanical compression of tissue in the gastrointestinal tract (5). The indications for treatment are closure of perforations and fistulas and control of non variceal gastrointestinal bleeding in which the conventional endoscopic treatment has failed $(6,7)$. To introduce margins of the lesion inside the OTSC, sometimes it is enough to apply constant suction or application aids may be used. A twin grasper with two branches which can be opening separately and an anchor are available (1). Two different configurations are available: The atraumatic version with blunt teeth, and the traumatic version with sharp teeth $(7,8)$, the choice between them depends on the kind of lesion to treat. One drawback of OTSC is that it is placed onto the tip of the scope, which makes the removal of the endoscope from the patient necessary (7) and it may be difficult to reach the lesion again.

Recently, Manta et al. (3) have published 30 cases of upper and lower gastrointestinal bleeding in which an OTSC was applied after failure of conventional endoscopic treatment (9). They got immediate hemostasis in 29 patients (97\%). In the only case were the OTSC failed, endovascular embolization guided by radiologic imaging was necessary. Another two cases suffered for rebleeding after 12 and 24 hours after the OTSC was placed, the hemorrhage stopped with injection of epinephrine and saline solution. No complications related to the procedure were related. In 2007, Kirschniak et al. reported 27 patients with gastrointestinal bleeding, hemostasis was achieved after OTSC placement, but two patients experienced a new episode of bleeding (5). In fact, in these two series of cases previously described, only one patient have a postpolypectomy bleeding.

In summary, OTSC system seems especially useful as an endoscopic treatment for gastrointestinal bleeding. In the two cases we reported, we achieved definitive hemostasis in postpolypectomy bleeding following placement of OTSC after failure of standard endoscopic treatment. A basic step in placement this device is center the lesion on the OTSC system to introduce edges of the lesion into the applicator cap. In the first case we report, the margin of the polypectomy cannot be adequately distinguished because of profuse bleeding, so it was necessary to use an anchor to introduce the tissue into the applicator cap. However, in the second patient, we could identify the edges of the polypectomy and the OTSC was centered on

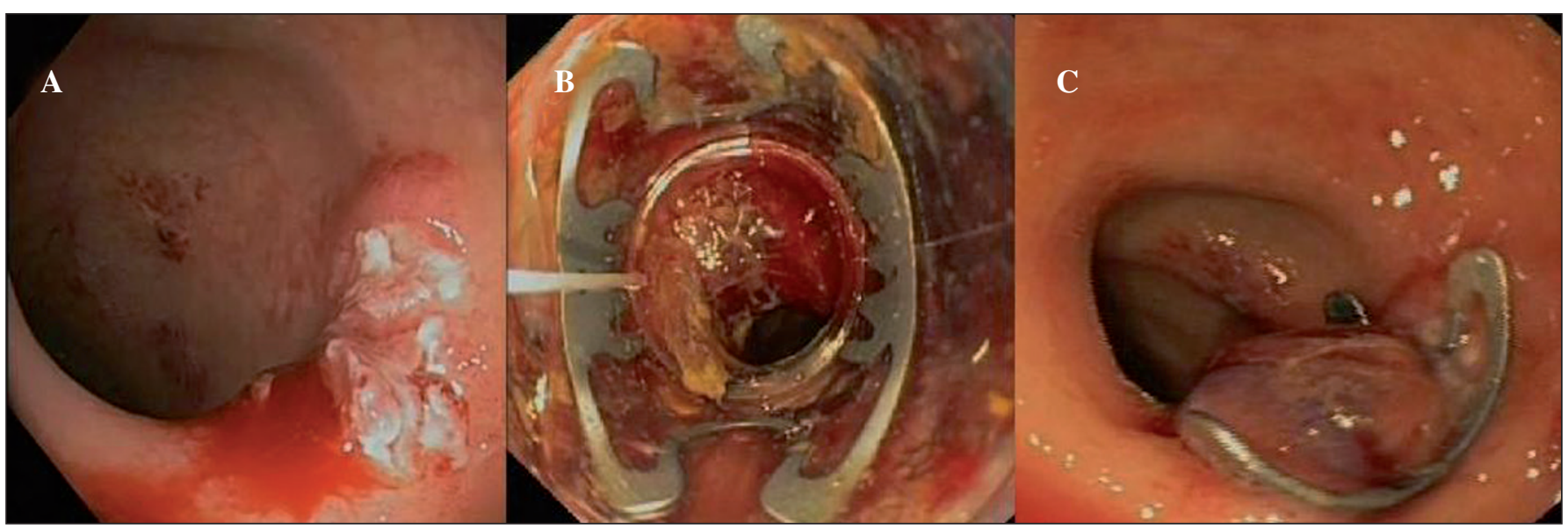

Fig. 5. Third bleeding. A. Bleeding ulcer caused by hemoclips. B. The ulcer is sucked into the cap with a loaded Ovesco. C. Placement of an Ovesco resulted in hemostasis. 
the lesion and it was successfully release after continuous suction. As a general rule, in non fibrotic tissues, it may not be required to use application aids and it is suggested to use OTSC with blunt teeth. Nevertheless, for fibrotic or chronic ulcers or fistulas, it is helpful to employ application aids like grasper and OTSC with sharp teeth (10). In most cases described in literature, OTSC is effective as the only endoscopic treatment for bleedings or other lesions. If necessary, other additional endoscopic devices can be used. The choice between them depends on the characteristic of the lesion, as stent, cyanocrylate injection or TTSCs. However, if the OTSC is released in an inaccurate way, it may prevent the use of other endoscopic devices.

In conclusion, OTSC is an effective, safe and easy device to use after a brief training period for gastroenterologist already familiarized with endoscopic variceal ligation. It may become an established endoscopic treatment for non variceal gastrointestinal bleeding which are difficult to control with other endoscopic treatments. Nevertheless, more studies with a large number of patients are indispensable to demonstrate its superiority over other endoscopic techniques and to establish recommendations indications, type of OTSC for every indication and patient.

\section{REFERENCES}

1. Albert JG, Friedrich-Rust M, Woeste G, Strey C, Bechstein WO, Zeuzem S, et al. Benefit of a clipping device in use in intestinal bleeding and intestinal leakage. Gastrointest Endosc 2011;74:389-97.

2. Repici A, Arezzo A, De Caro G, Morino M, Pagano N, Rando G, et al. Clinical experience with a new endoscopic over-the-scope clip system for use in the GI tract. Dig Liver Dis 2009;41:406-10.

3. Manta R, Manno M, Bertani H, Barbera C, Pigò F, Mirante V, et al. Endoscopic treatment of gastrointestinal fistulas using an over-thescope clip (OTSC) device: Case series from a tertiary referral center. Endoscopy 2011;43:545-8

4. Díez-Redondo P, Blanco JI, Lorenzo-Pelayo S, De-la-Serna-Higuera C, Gil-Simón P, Alcaide-Suárez N, et al. A novel system for endoscopic closure of iatrogenic colon perforations using the Ovesco ${ }^{\circledR}$ clip and omental patch. Rev Esp Enferm Dig 2012;104:550-2.

5. Kirschniak A, Subotova N, Zieker D, Königsrainer A, Kratt T. The Over-The-Scope Clip (OTSC) for the treatment of gastrointestinal bleeding, perforations, and fistulas. Surg Endosc 2011;25:2901-5.

6. Mönkemüller K, Toshniwal J, Zabielski M, Vormbrock K, Neumann H. Utility of the "bear claw", or over-the-scope clip (OTSC) system, to provide endoscopic hemostasis for bleeding posterior duodenal ulcers. Endoscopy 2012;44(Supl. 2 UCTN):E412-3.

7. Kirschniak A, Kratt T, Stüker D, Braun A, Schurr MO, Königsrainer A. A new endoscopic over-the-scope clip system for treatment of lesions and bleeding in the GI tract: First clinical experiences. Gastrointest Endosc 2007;66:162-7.

8. Junquera F, Martínez-Bauer E, Miquel M, Fort M, Gallach M, Brullet E, et al. OVESCO: A promising system for endoscopic closure of gastrointestinal tract perforations. Gastroenterol Hepatol 2011;34:568-72.

9. Manta R, Galloro G, Mangiavillano B, Conigliaro R, Pasquale L, Arezzo A, et al. Over-the-scope clip (OTSC) represents an effective endoscopic treatment for acute GI bleeding after failure of conventional techniques. Surg Endosc 2013;27:3162-4.

10. Baron TH, Song LM, Ross A, Tokar JL, Irani S, Kozarek RA. Use of an over-the-scope clipping device: Multicenter retrospective results of the first U.S. experience (with videos). Gastrointest Endosc 2012;76:202-8 